\title{
Manifestaciones dermatológicas asociadas a la infección por VIH/SIDA
}

\author{
Cristián Navarrete-Dechent, Rinna Ortega, Félix Fich y Marcela Concha
}

\section{Dermatologic manifestations associated with HIV/AIDS}

The ongoing human immunodeficiency virus (HIV) infection epidemic coupled with more efficacious and available treatments has led to a larger number of patients living with HIV or AIDS. As a result, skin manifestations related to HIV/AIDS or its therapy have become increasingly more common and are reported to occur in as many as $95 \%$ of patients. Herein, we review the most common HIV/AIDS related cutaneous pathologies and classify them into inflammatory, HAART-associated, neoplastic, and infectious manifestations. Cutaneous manifestations should be promptly recognized and treated by physicians and health care personnel in order to provide optimal care.

Key words: HIV, skin, dermatology, AIDS.

Palabras clave: VIH, piel, dermatología, SIDA.

\section{Introducción}

$\mathrm{E}$ 1 VIH (virus de la inmunodeficiencia humana) es un retrovirus del género lentivirus causante del síndrome de inmunodeficiencia adquirida (SIDA), cuadro descrito hace ya tres décadas ${ }^{1}$. Se conocen dos subtipos: el VIH-1 y el VIH-2, siendo el primero el más común y de distribución mundial, mientras que el segundo, una variante menos virulenta, es prevalente en África Occidental y Central ${ }^{1-4}$.

Se estima que existían 34,2 millones de personas infectadas por VIH al año 2011, en comparación con 29,1 millones el año 2001. El año 2011 se infectaron 2,5 millones de personas y murieron 1,7 millones, lo cual marca una reducción de $22 \%$ en contagio en comparación al año 2001 y $26 \%$ de reducción en muertes en comparación al año $2005^{1,5}$. Sin embargo, estos números están marcados por una gran dispersión: África sub-sahariana es la zona más afectada, seguida por Europa del Este y el Caribe ${ }^{1}$. Los números son alarmantes: $31 \%$ de la población de Suazilandia, $25 \%$ de Botsuana y $17 \%$ de Sudáfrica está infectada por el $\mathrm{VIH}^{1}$. Aún más, $54 \%$ de las mujeres entre 30 y 34 años está infectada en Suazilandia ${ }^{1}$.

En Chile, el primer caso de VIH/SIDA se notificó el año 1984. Entre 1984 y 2012 se han notificado 29.092 casos $^{6}$.

\section{Manifestaciones cutáneas del VIH/SIDA y fisiopatología}

El número de pacientes con VIH/SIDA que desarrollará algún tipo de manifestación cutánea varía según la serie, pero fluctúa entre 40 y $95 \%{ }^{7,8}$.

Hoy en día, se sabe que las manifestaciones dermatológicas no ocurren solamente debido a la disminución en los linfocitos T CD4, sino que también debido a un cambio en el perfil de citoquinas hacia un perfil predominantemente Thelper 2 (Th2), mimetismo molecular y la sobre-expresión de superantígenos/xenobióticos ${ }^{9}$.

Los pacientes infectados por VIH experimentan una disminución marcada en el número de células de Langerhans, LTCD4, células NK, macrófagos y monocitos; esto explicaría el mayor número de infecciones cutáneas debido a una disminución en los LTCD4 pero además se ha descrito una menor vigilancia por las células de Langerhans ${ }^{9}$. El cambio en el perfil de citoquinas de $\mathrm{T}$ helper 1 (Th1) a Th2 puede explicar la aparición o exacerbación de enfermedades no infecciosas como la dermatitis atópica. Por otro lado, hay inversión de la relación LTCD4/LTCD8 (valor normal > 1); activación policlonal de linfocitos B, con aumento en las gamaglobulinas y producción de autoanticuerpos y fenómenos autoinmunes ${ }^{10}$. Las concentraciones de algunas citoquinas como el IFN $\gamma$ y el FNT $\alpha$ aumentan, mientras que las IL-1 y 2 disminuyen ${ }^{10}$.

Las manifestaciones cutáneas de la infección por VIH/ SIDA pueden dividirse en no-infecciosas (inflamatorias, asociadas o no a la terapia anti-retroviral [TARV] o neoplásicas) y en infecciosas (excluyendo en estas últimas las causadas por la infección del VIH en sí).

Las segundas pueden subdividirse según su etiología en bacterianas, virales, fúngicas y parasitarias. El agrupar las manifestaciones cutáneas de esta manera, facilita sistematizar las posibles etiologías y ayuda el momento de enfrentarse a los pacientes (Tabla 1).
Facultad de Medicina, Pontificia Universidad Católica de Chile, Santiago, Chile. Departamento de dermatología (CND, FF, MC). Clínica INDISA, Santiago, Chile. Departamento de Dermatología (RO).

Los autores declaran no tener conflictos de interés.

Recibido: 16 de diciembre de 2013 Aceptado: 7 de abril de 2014

Correspondencia a: Cristián Navarrete-Dechent ctnavarr@gmail.com 


\section{Tabla 1. Manifestaciones cutáneas asociadas a la infección por VIH/SIDA}

Inflamatorias (no infecciosas-no neoplásicas no asociadas a TARV)

Síndrome retroviral agudo o infección primaria del VIH

Dermatitis seborreica

Psoriasis

Dermatitis atópica y xerosis

Foliculitis eosinofílica y erupción pruriginosa papular

Manifestaciones asociadas a TARV (no infecciosas-no neoplásicas )

Reacciones adversas a TARV

Síndrome de reconstitución inmunológica

Manifestaciones neoplásicas

Sarcoma de Kaposi

Neoplasias cutáneas

Neoplasia anal intraepitelial y cáncer anal

Manifestaciones infecciosas asociadas a VIH

Bacterianas

Virales

Fúngicas

Parasitarias

TARV: terapia anti-retroviral
Manifestaciones no infecciosas

la fiebre puede aparecer un rash cutáneo morbiliforme (Figura 1), pápulo-escamoso o vesicular en el tronco superior, cabeza y cuello, que luego se disemina en forma centrífuga a las palmas y plantas ${ }^{12}$. Pueden haber úlceras orales y úlceras genitales dolorosas ${ }^{11}$. Además se pueden encontrar mialgias y artralgias; faringitis, diaforesis, náuseas, vómitos, diarrea, baja de peso y anorexia, entre otros $^{13}$

Debido a que la seroconversión comienza a partir de la segunda semana desde el contagio, el resultado del ELISA puede ser negativo y el diagnóstico no hacerse de forma correcta, por lo que debe tenerse un alto índice de sospecha y repetir los tests serológicos si persiste la duda diagnóstica ${ }^{11}$.

\section{Dermatosis misceláneas}

Patologías que son usuales en la población general pueden presentarse de manera atípica, de forma más intensa o con una mayor frecuencia que en los pacientes no infectados por el VIH. En general, el tratamiento es el habitual para cada patología pero como pueden presentarse de forma grave, en algunos casos se requieren tratamiento iniciales más intensos. Por otro lado, deben considerarse las interacciones farmacológicas con la TARV al momento de elegir el tratamiento para cada patología.

\section{Síndrome retroviral agudo o infección primaria por VIH}

Se observa en 50 a $90 \%$ de los individuos que adquieren la infección durante los primeros seis meses desde el contagio pero es generalmente confundido con una "virosis inespecífica" o con una mononucleosis infecciosa ${ }^{11}$. Es la manifestación más temprana de la infección por VIH y se asocia con altos niveles de replicación viral; los síntomas comienzan de manera abrupta entra las 2 y 4 semanas desde la adquisición del virus ${ }^{12,13}$.

Se caracteriza clínicamente por fiebre hasta $40^{\circ} \mathrm{C}$ y compromiso del estado general. A las 48-72 h de iniciada

Figura 1. Rash morbiliforme en tronco de paciente con síndrome retroviral agudo.

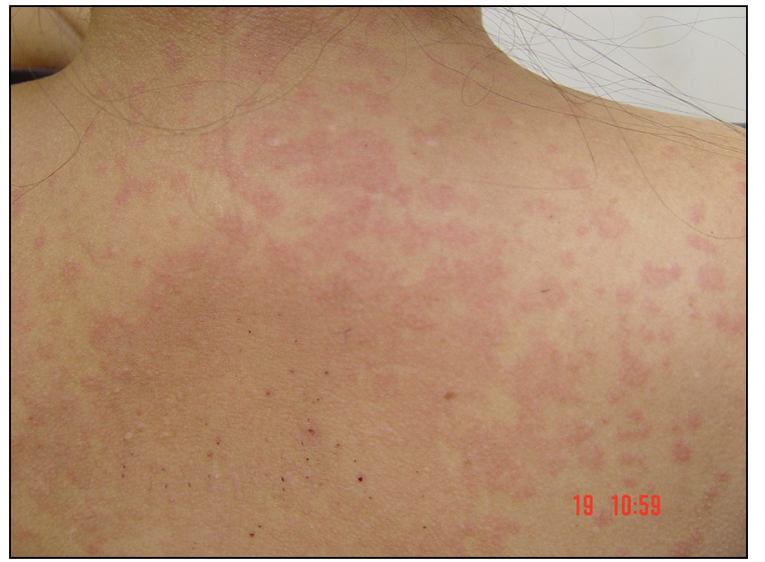

\section{Dermatitis seborreica}

La dermatitis seborreica (DS) se presenta en 2 a $4 \%$ de la población general; sin embargo, en los pacientes con infección por VIH/SIDA es significativamente mayor, llegando a $85 \%$ en algunas series ${ }^{9,10,14}$. La aparición de esta dermatosis y su gravedad se relacionan al número de LTCD4 del paciente (4,7-42\% en etapas iniciales y $26,7-$ $83 \%$ en etapas más tardías/SIDA según la serie $)^{10,15,16}$. Se han reportado formas diseminadas o eritodérmicas de DS con compromiso de la región facial, esternón, dorso, axilas e ingles ${ }^{10}$.

Respecto a la patogenia, se discute el rol de la reacción de hipersensibilidad a Malassezia spp y su asociación con la DS.

La DS puede ser uno de los primeros indicadores de infección por VIH, por lo cual en toda DS atípica, extensa o que no responda a tratamiento debe solicitarse serología para VIH.

Si la DS es localizada puede utilizarse tratamiento tópico, al igual que en los individuos inmunocompetentes. En casos más intensos se requieren tratamientos con antifúngicos sistémicos e incluso fototerapia ${ }^{16}$.

\section{Psoriasis}

Esta enfermedad afecta aproximadamente a 2-3\% de la población general. La prevalencia en los pacientes infectados con VIH es similar a la de los seronegativos; 
sin embargo, la enfermedad tiende a ser más intensa, acral, extensa, destructora y recalcitrante. Cabe destacar que tienen mayor frecuencia de artritis psoriásica9 ${ }^{9}$ Se ha descrito la aparición de psoriasis como marcador de infección por el VIH en pacientes previamente sanos. La aparición de psoriasis en pacientes con factores de riesgo debe hacer sospechar el contagio con el VIH y es una indicación para realizar pruebas serológicas para descartar este contagio ${ }^{9,10}$. Por otra parte, el curso de la psoriasis empeora con la progresión de la enfermedad y podría ser un marcador de progresión a etapa SIDA $^{10}$.

Se ha visto que el VIH tiene un efecto proliferativo epidérmico en los queratinocitos per se, además de las alteraciones inmunológicas que produce, como la disminución en las células de Langerhans y la alteración de la relación LTCD4/LTCD89.

El inicio de la TARV puede ayudar en el tratamiento de la psoriasis y producir una mejor respuesta a los tratamientos tópicos ${ }^{16}$. Los agentes inmunosupresores y los biológicos están actualmente en estudio para evaluar su posible uso en pacientes infectados con VIH; publicaciones recientes sugieren que metrotrexato, ciclosporina, etanercept e infliximab podrían ser utilizados en ciertas circunstancias ${ }^{17}$.

Los retinoides orales, comúnmente usados en el tratamiento de la psoriasis en pacientes seronegativos, deben emplearse con cautela en usuarios de inhibidores de proteasa (IP) ${ }^{16}$.

\section{Dermatitis atópica y xerosis}

La dermatitis atópica (DA) es una enfermedad inflamatoria crónica. Se presenta en 30 a $50 \%$ de los pacientes con infección por VIH en comparación a 2-20\% de la población seronegativa. La patogénesis de esta enfermedad y la infección por VIH se ha asociado a la hipereosinofilia y las concentraciones elevadas de IgE secundarias al desbalance Th1-Th2 de estos pacientes ${ }^{9,14}$. Además, presentan mayor tasa de colonización por Staphylococcus aureus, con mayor presencia de superantígenos ${ }^{9}$. Del mismo modo, los pacientes con infección por VIH tienen mayor incidencia de xerosis, con más de $20 \%$ de prevalencia, siendo una de las causas importantes de prurito en este grupo $^{18}$.

El tratamiento es similar al de pacientes no infectados por el VIH; sin embargo, los corticosteroides sistémicos deben usarse con especial cautela ${ }^{16}$.

\section{Fotodermatosis}

La fotosensibilidad es más frecuente y grave en los pacientes con infección por VIH; además empeora de manera directa con el grado de inmunosupresión. Se presenta frecuentemente con erupciones liquenoides o con forma de eczema/dermatitis en zonas fotoexpuestas ${ }^{16}$. La fotosensibilidad puede ser causada de manera directa por el VIH o, de forma más frecuente, por los fármacos antivirales y/o antibacterianos usados como profilaxis de infecciones oportunistas. La fotosensibilidad asociada a la infección por VIH ocurre con recuentos de LTCD4 $<50$ céls $/ \mathrm{mm}^{3}{ }^{14}$.

Cotrimoxazol es la causa más frecuente de fotosensibilidad en este grupo de pacientes y puede manifestarse como reacción fotoalérgica o fototóxica ${ }^{14,16}$.

Otras causas menos frecuentes son la porfiria cutánea tarda en el contexto de una co-infección por virus de hepatitis $\mathrm{C}$ y reacciones tipo pelagra por malnutrición y déficit de vitamina $\mathrm{B} 3{ }^{16}$.

\section{Prurito, foliculitis eosinofilica y erupción pruriginosa papular}

El prurito es uno de los síntomas prominentes de los pacientes infectados por VIH y puede ser uno de los primeros o el único síntoma a presentarse ${ }^{10,16}$. Por un lado, el prurito sin causa explicada debe elevar la sospecha de infección por VIH e inducir a solicitar pruebas serológicas para la detección del mismo; por otro lado, los pacientes con infección por VIH que presentan prurito deben ser estudiados para descartar otras causas subyacentes de prurito no explicado, como enfermedades renales, hepáticas $\mathrm{y}$ desórdenes hematológicos, entre otros ${ }^{16}$.

La foliculitis eosinofílica (FE) es una enfermedad cutánea crónica, de causa desconocida, que se presenta en pacientes con infección por VIH avanzada. La FE se divide en tres grandes grupos: la FE clásica o enfermedad de Ofuji, la FE infantil y la FE asociada a inmunosupresión; es esta última variante la que se presenta en este grupo de pacientes ${ }^{19}$.

Se presenta como pápulas y pústulas foliculares y no foliculares en la cara, cuello, cuero cabelludo, tronco superior (en la línea media) y región proximal de extremidades. Respeta las palmas y plantas, lo que la diferencia de la enfermedad de Ofuji ${ }^{16}$. El diagnóstico se realiza con la historia clínica, el examen físico y la histología.

La FE se caracteriza por infiltrados eosinofílicos perifoliculares a nivel del istmo y ducto sebáceo ${ }^{14}$ con lisis sebáce ${ }^{20}$ y cultivos bacterianos y micológicos negativos ${ }^{14}$. Puede haber eosinofilia en la sangre periférica y una relación $\mathrm{LTCD} 8 / \mathrm{CD} 4>10: 1^{20}$. Se ha tratado de atribuir un factor infeccioso a la FE pero no se ha encontrado; se cree que el ácaro Demodex spp podría inducir una disregulación inmunológica, produciendo al menos en parte, la FE.

La enfermedad aparece con LTCD4 $<200-250$ céls/ $\mathrm{mm}^{316}$. Los casos leves de enfermedad responden a anti histamínicos ${ }^{20}$, corticosteroides tópicos y escabicidas. En casos más graves debe usarse antimicóticos orales, retinoides sistémicos y/o fototerapia. Por último, la FE se puede exacerbar como parte del síndrome de reconstitución inmunológica, como se comenta más adelante ${ }^{16}$. 
La erupción pruriginosa papular (EPP) es considerada por algunos autores como una variante de la FE y por otros como un espectro de enfermedad ${ }^{21}$. La EPP se presenta en 11 a $46 \%$ de los pacientes con VIH en los trópicos, donde es mucho más frecuente.

Se caracteriza por pápulas discretas, intensamente pruriginosas. A diferencia de la FE, tiene una distribución más distal, con menos compromiso de tronco y compromiso marcado en las extremidades. Los que consideran la EPP como una entidad aparte barajan la hipótesis de una respuesta exagerada a mordeduras de artrópodos. La enfermedad empeora con recuentos bajos de LTCD4 y mejora con la restitución de la inmunidad ${ }^{16,22}$.

\section{Manifestaciones asociadas a TARV (no infecciosas-no neoplásicas)}

Los pacientes con infección por VIH tienen un mayor riesgo de experimentar reacciones adversas a medicamentos (RAM) mediadas inmunológicamente en comparación a la población sana, debido a disregulación de su sistema inmune y al gran número de fármacos que consumen ${ }^{4}$. Las toxicodermias ocurren en aproximadamente 3 a $22 \%$ de estos pacientes ${ }^{4,23,25}$.

De esta misma manera, el uso de TARV en pacientes infectados por VIH no está exento del riesgo de desarrollar una RAM inmunológica. Los efectos adversos de la TARV incluyen varios puramente dermatológicos, como por ejemplo: efectos retinoide-símil (paroniquia, xerosis cutánea intensa, alopecia, granuloma telangiectásico y queilitis), lipodistrofia (caracterizado por redistribución de la grasa corporal con pérdida de grasa periférica, aumento de la grasa central, hipertrofia mamaria y aumento de la grasa dorso-cervical asociado a anormalidades metabólicas), erupción morbiliforme (Figura 2) y síndrome de Stevens-Johnson; entre otros ${ }^{4}$. En la Tabla 2 se resumen los efectos adversos dermatológicos más comunes de la TARV según la familia del fármaco.

\section{Síndrome de reconstitución inmunológica (SRI)}

Se presenta con posterioridad al inicio de la TARV $\mathrm{y}$ tiene un amplio espectro de manifestaciones. Ocurre debido a que el paciente recupera su capacidad para desarrollar una respuesta inmunológica y comienza a reconocer múltiples microorganismos ${ }^{26}$.

La respuesta inflamatoria puede ser a agentes infecciosos, como micobacterias, hongos oportunistas y diferentes tipos de virus (herpes simplex, virus papiloma humano) presentes al momento del inicio de los antivirales, produciéndose un empeoramiento paradojal del paciente pese al aumento en el recuento de LTCD $4^{26}$. Además, existen múltiples reportes de casos que muestran exacerbaciones de infecciones subclínicas a otros agentes infecciosos no mencionados. Sumado a esto, pueden empeorar patologías inflamatorias como la sarcoidosis, FE y DA ${ }^{26}$.

Algunas series han mostrado una prevalencia de SRI de $25 \%$; en general ocurre en pacientes de alto riesgo durante las primeras ocho semanas de iniciada la TARV: aquellos que inician TARV con un recuento de LTCD4 bajo (menor a 200 céls $/ \mathrm{mm}^{3}$ ) y aquellos con infecciones subclínicas al momento de iniciar la terapia ${ }^{24,26}$.

\section{Manifestaciones neoplásicas}

\section{Sarcoma de Kaposi}

El sarcoma de Kaposi (SK) es una de las entidades clínicas que llevó a la definición de la infección por VIH/SIDA como una nueva enfermedad. Se conocía su característica de "oportunista" y su asociación al virus herpes tipo 8 (VHH-8) debido a su aparición en pacientes receptores de trasplantes ${ }^{10}$. El VHH-8 es un virus ADN que se transmite sexualmente o a través de la sangre ${ }^{27}$. El SK se clasifica en cuatro tipos, siendo la variante epidémica la asociada al VIH.

La incidencia del SK en pacientes infectados por VIH, en los primeros años de descripción de esta enfermedad, llegaba a $30-40 \%$, afectando principalmente a hombres

\section{Tabla 2. Manifestaciones cutáneas más frecuentes asociadas a las terapias anti-retrovirales}

\section{Grupo de anti-retrovirales}

Inhibidores de transcriptasa reversa nucleosídicos (ITRN)
Manifestaciones dermatológicas

Lipodistrofia (todos los ITRN pero principalmente stavudina y didanosina), hiperpigmentación de mucosas e hiperpigmentación longitudinal de uñas (zidovudina; más frecuente a mayores dosis), rash de cualquier tipo (parte del diagnóstico de síndrome de hipersensibilidad a abacavir), otros (hipertricosis de las pestañas, urticaria, vasculitis leucocitoclástica)

Inhibidores de transcriptasa reversa no-nucleosídicos (ITRNN)

Inhibidores de proteasa

Inhibidores de entrada y de fusión

Inhibidores de integrasa
Rash (exantema) morbiliforme (los más frecuentes, en general durante el primer mes de terapia) hasta $28 \%$ con nevirapina y hasta $34 \%$ con efavirenz. Deben ser observados de cerca por el riesgo de progresar a síndrome de Stevens-Johnson o un síndrome de DRESS

Lipodistrofia (todos), rash (es muy poco frecuente, el más común es morbiliforme), ictericia (frecuente con atazanavir), efecto retinoide símil y onicocriptosis (indinavir)

Reacciones del sitio de inyección (68-98\% con enfuvirtide, incluyen reacciones escleróticas del sitio), rash (16,5\% con maraviroc) Raros los efectos cutáneos (menos de 2\%)

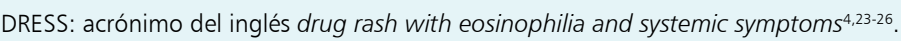




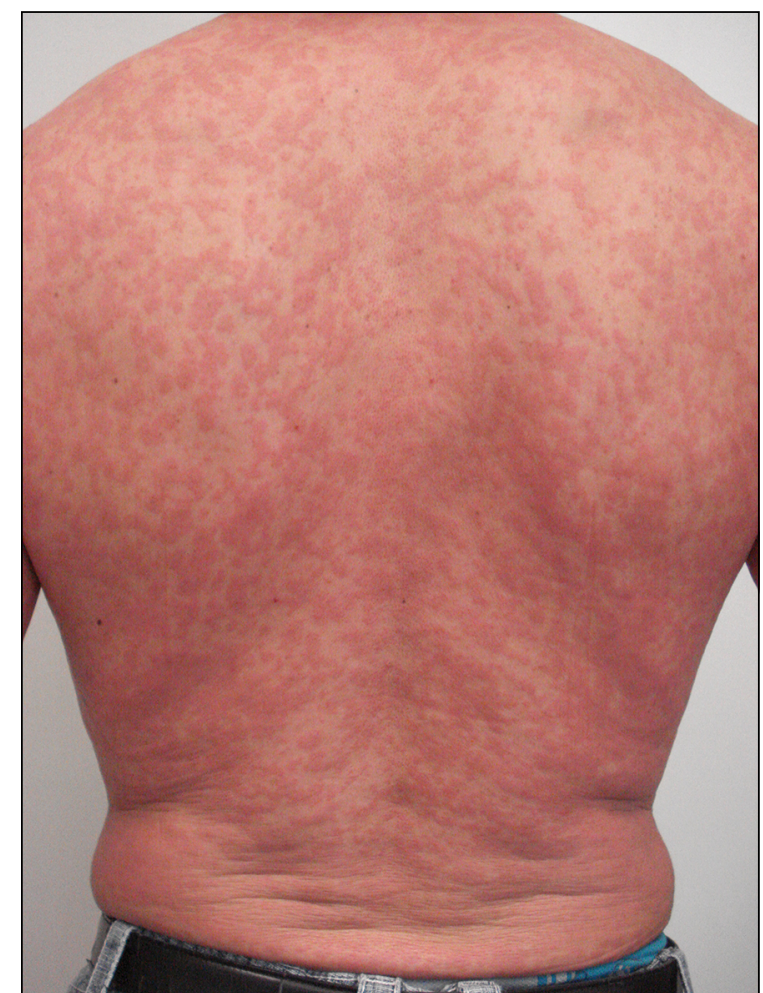

Figura 2. RAM por ITRNN.

homosexuales. Actualmente ha disminuido su frecuencia llegando a $10 \%$ de los pacientes; esto, sumado al advenimiento de la TARV combinada disminuyó su mortalidad en $81 \%{ }^{10}$.

Se presenta como máculas, placas o nódulos eritemato-violáceos brillantes, asintomáticos, clásicamente distribuidos en las líneas de Langer ${ }^{27}$. A diferencia de otras patologías que pueden comprometer la mucosa de manera similar al SK, este último clásicamente afecta el paladar duro.

El SK diseminado afecta frecuentemente órganos sólidos: pulmones y tracto gastrointestinal, principalmente. Cuando se presenta como una neoplasia multisistémica, se asocia a baja tasa de supervivencia (Figuras $3 a$ y $3 b$ ).

Todo paciente con SK debe iniciar TARV con un IP asociado, esto debido a que los IP han demostrado inhibir la angiogénesis del tumor ${ }^{27}$.

La etapa precoz del SK se define si el paciente cumple todos los siguientes criterios: SK limitado a la piel con mínimo compromiso de mucosa oral -máculas sólo en el paladar duro-; CD4 > 200/ $\mathrm{mm}^{3}$; sin infecciones oportunistas; sin candidiasis oral y sin síntomas B. En estos casos, el tratamiento puede realizarse sólo con TARV que incluya IP.

Por el contrario, en la etapa tardía, definida como pacientes con SK que cumplan cualquiera de los siguientes criterios: SK pulmonar o gastrointestinal; compromiso

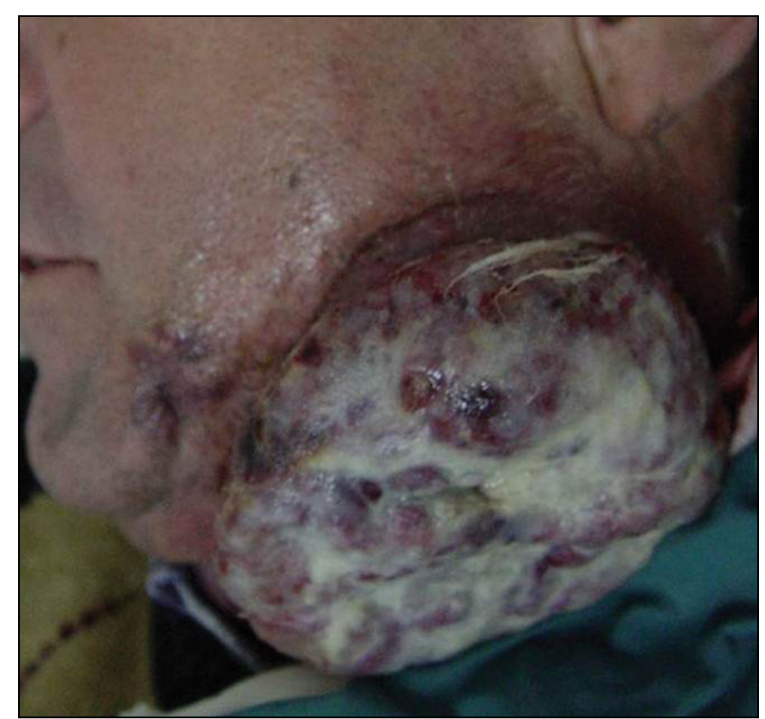

Figura 3a. Tumor eritematovioláceo en el cuello de un paciente con sarcoma de Kaposi con compromiso sistémico.

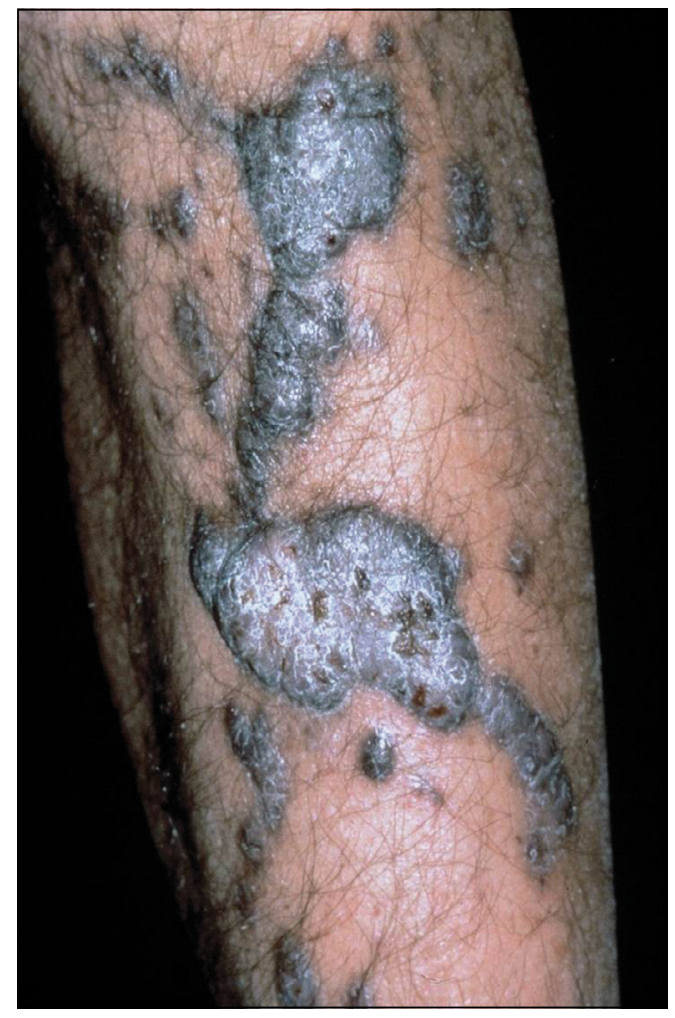

Figura 3b. Sarcoma de Kaposi. Múltiples tumores violáceos en la cara anterior de la pierna.

oral excesivo; ulceraciones tumorales; CD4 < 200; paciente con historia de infecciones oportunistas; algorra; o síntomas B; el tratamiento debe realizarse con TARV que incluya IP asociado a antraciclinas liposomales como doxorubicina ${ }^{27}$.

El valganciclovir podría ser una alternativa en la prevención del SK debido a que ha mostrado suprimir al VHH-8. Sin embargo, se trata de evidencia experimental y muy precoz ${ }^{28}$. 


\section{Neoplasias cutáneas}

Los pacientes con infección por VIH tienen mayor incidencia de carcinomas cutáneos como el carcinoma espinocelular y carcinoma basocelular principalmente, agrupados como "cáncer de piel no melanoma (CPNM)"22. El riesgo de desarrollar CPNM se encuentra aumentado en 2,1 veces en comparación con la población no infectada por VIH. En el caso del carcinoma espinocelular este riesgo es inversamente proporcional al conteo de LTCD4. Esta asociación no ha sido demostrada para carcinomas basocelulares $^{30}$.

Del mismo modo, el riesgo de melanoma también se encuentra aumentado y es $26 \%$ mayor a la población general. Este riesgo permanece elevado aún en la era post TARV ${ }^{31}$.

Por esta razón, recomendamos que los pacientes con infección por VIH deben ser evaluados al menos una vez al año en búsqueda de cáncer de piel tanto melanoma como no melanoma.

\section{Neoplasia anal intraepitelial y cáncer anal}

El cáncer anal ha aumentado su incidencia desde el advenimiento del VIH y representa la neoplasia más frecuente no definitoria de SIDA en los pacientes con infección por VIH homosexuales ${ }^{32}$. La incidencia de cáncer anal en los pacientes con VIH es alrededor de 40 a $137 / 1.000$ personas-año ${ }^{33}$.

Pese a que los condilomas acuminados son clásicamente benignos, aproximadamente $50 \%$ de los condilomas anales grandes pueden contener neoplasia anal intraepitelial (NAI) de alto grado o un cáncer escamoso anal en el grupo de pacientes de alto riesgo (Figura 4). Por lo tanto, la infección perianal y genital con virus papiloma humano (VPH) de tipos oncogénicos de alto riesgo puede llevar al desarrollo de NAI que es clínicamente no palpable, con posterior desarrollo de cáncer anal. De este modo, uno de los principales factores de riesgo para desarrollar cáncer anal en los pacientes con infección por VIH es la portación crónica de VPH de alto riesgo ${ }^{33}$.

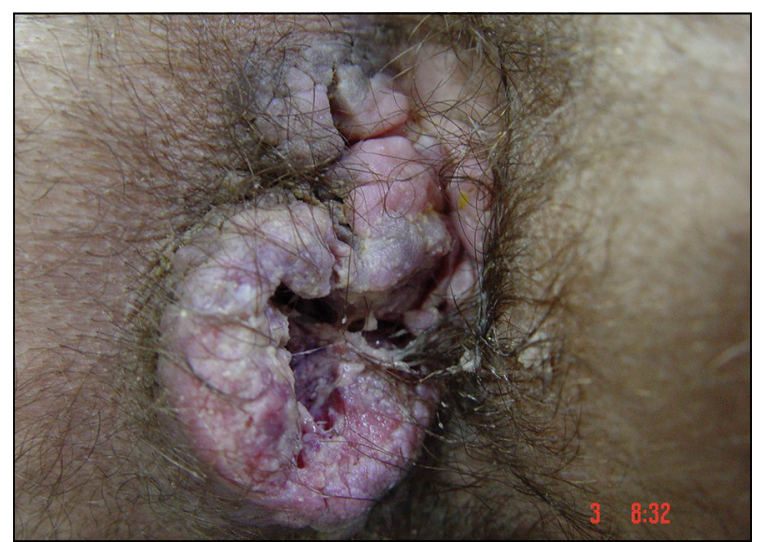

Un estudio alemán mostró que los pacientes infectados con VIH-homosexuales tenían un 35\% de NAI de alto grado y $2,5 \%$ tuvo carcinoma anal ${ }^{31}$.

En otro estudio llevado a cabo en España, se incluyeron pacientes homosexuales infectados con VIH a los que se les realizó Papanicolaou (PAP), biopsia anal y estudio molecular de VPH; más de $50 \%$ de los pacientes tuvo displasia anal al PAP, la mayoría de bajo grado. De ellos, $88 \%$ fue positivo para VPH y $74 \%$ fue positivo para VPH de alto riesgo. Uno de los resultados más llamativos fue que a la histología $11,4 \%$ mostró un carcinoma in situ. Otro resultado interesante fue que si el PAP fue normal y el estudio molecular de VPH no mostró genotipos de alto riesgo, $75 \%$ tuvo histología normal y los que la tuvieron alterada tuvieron NAI grado 1. La TARV de larga data es un factor protector ${ }^{33}$. Es imperativo montar protocolos de screening de cáncer anal en este grupo de pacientes, población con un riesgo aumentado 28 veces $^{35}$.

\section{Cáncer de pene}

Al parecer, la mucosa del pene es menos susceptible a la infección por VPH y existe un menor riesgo de transformación maligna; sin embargo, se ha visto que aproximadamente $4,2 \%$ de los pacientes con infección por VIH y homosexuales tiene neoplasia intraepitelial peneana (NIP). Este riesgo es mayor frente a la presencia de NAI y llega hasta $8,5 \%$ de los pacientes con NAI de alto grado ${ }^{34,36}$. Pese a la presencia de NIP, el riesgo de cáncer de pene invasor es bajo; sin embargo, se encuentra aumentado 4,42 veces ${ }^{35}$. Los tipos clínicos de NIP son: bowenoide, verrucoso, eritroplásico y leucoplásico. Sólo un pequeño porcentaje de los NIP evolucionará a cáncer de pene invasor, incluso en presencia de NIP de alto grado ${ }^{36}$.

\section{Manifestaciones infecciosas asociadas a VIH}

Las infecciones son una causa frecuente de manifestación muco-cutánea de la infección por $\mathrm{VIH}^{8}$. Múltiples agentes bacterianos, virales, fúngicos o parasitarios pueden producir infecciones en este grupo de pacientes.

\section{Bacterianas}

El grupo principal de bacterias que cause infecciones cutáneas son las especies grampositivas; de ellas, la principal es Staphylococcus aureus. En este grupo de pacientes debe recordarse la posibilidad de que la infección sea causada por S. aureus resistente a meticilina (SARM) ${ }^{37}$, llegando a una tasa de portación de $8,2 \%$ comparado con $3 \%$ en la población sin VIH pero con los mismos factores de riesgo. De estos pacientes seropositivos para VIH, colonizados con SARM, 55\% desarrolló una infección posterior $^{30}$. Del mismo modo, la incidencia de SARMadquirido en la comunidad (SARM-AC), es seis veces más
Figura 4. Paciente con tumor ulcerado en la región perianal. La biopsia confirmó el diagnóstico de carcinoma anal. 
frecuente en pacientes con infección por VIH. Además, la recurrencia de estas piodermias es alta, con recidivas de $41 \%$ a cuatro meses ${ }^{32}$. El número de infecciones y la tasa de recurrencia disminuye significativamente con la disminución de la carga viral ${ }^{32}$.

Las formas más comunes de presentación son la foliculitis, el impétigo y la celulitis; también puede manifestarse como ectima, forúnculos, ántrax y abscesos. Suelen tener un curso localmente agresivo, que puede llegar a cuadros de sepsis y bacteriemia. Se localizan en las extremidades inferiores, glúteos y escroto, con mayor frecuencia que en las extremidades superiores y la cara ${ }^{32}$. No se ha encontrado resistencia a cotrimoxazol en las series publicadas de SARM-AC ${ }^{37}$.

Pseudomonas aeruginosa puede causar infecciones primarias tales como la infección de catéteres o en las regiones ano-genital y axilar. Además, puede causar infección secundaria de otras dermatosis como el sarcoma de Kaposi o por diseminación hematógena a la piel, cuadro conocido como ectima gangrenoso.

\section{Micobacterias}

La tuberculosis (TBC) es una infección oportunista común en la enfermedad por $\mathrm{VIH}^{38,39}$. La TBC cutánea representa sólo 1 a $2 \%$ de los casos de TBC y puede ocurrir por inoculación cutánea primaria o por diseminación sistémica. La prevalencia de TBC cutánea podría estar aumentando en los casos de pacientes con infección por $\mathrm{VIH}^{40}$.

La expresión clínica es diversa pero se puede presentar como pápulas y placas costrosas induradas diseminadas en los casos de diseminación cutánea desde una TBC sistémica pulmonar o meníngea, cuadro que es denominado TBC miliar cutánea generalizada aguda. Se incluye dentro del diagnóstico diferencial de lesiones "moluscoides" que se detallará más adelante ${ }^{41}$.

Por otro lado, las micobacterias atípicas o micobacterias no tuberculosas son bacilos ácido-alcohol resistentes, ubicuos en la naturaleza. Incluyen a las siguientes especies: M. avium complex, M. bovis, M. kansasii, M. marinum, M. malmoense, M. ulcerans, M. chelonae, M. fortuitum y M. abscessus, entre otros. Los últimos tres corresponden a especies de crecimiento rápido según la clasificación de Runyon ${ }^{42,43}$. Su incidencia está aumentando, en parte por la diseminación del $\mathrm{VIH}^{42}$.

El compromiso cutáneo se caracteriza por abscesos, forúnculos, tractos profundos que drenan hacia la piel o seromas indolentes ${ }^{43}$. Además, se pueden presentar como placas o nódulos verrucosos, ulcerados, en las extremidades superiores, sobre todo en el caso de M. marinum $^{39}$. Se debe sospechar infección por micobacterias atípicas en cualquier paciente con lesiones nodulares profundas, principalmente con posterioridad a la exposición de ambientes húmedos, a trauma local o masoterapia ${ }^{43}$.
El agente micobacteriano más frecuente distinto a Mycobacterium tuberculosis que provoca enfermedad en SIDA avanzado es el complejo Mycobacterium avium complex (MAC), aunque rara vez produce manifestaciones cutáneas ${ }^{44}$. Las lesiones cutáneas por MAC, a diferencia de las causadas por $\mathrm{TBC}$, se desarrollan en etapas más tardías de la infección por $\mathrm{VIH}^{41}$.

\section{Angiomatosis bacilar}

La angiomatosis bacilar y peliosis hepática bacilar son expresiones poco frecuentes de infecciones causadas por Bartonella henselae y B. quintana; se producen más comúnmente en etapa avanzada de SIDA (menos de $\left.200 \mathrm{LTCD} 4 / \mathrm{mm}^{3}\right)^{10}$. Se caracterizan por lesiones angioproliferativas que semejan hemangiomas en cereza, granulomas piógenos o sarcoma de Kaposi, como pápulas cupuliformes, nódulos o placas de color rojo a violáceas la mayoría de las veces diseminadas (Figura 5) ${ }^{45}$. Los antimicrobianos de elección son macrólidos o doxiciclina. En nuestra experiencia, se han usado azitromicina y ciprofloxacina con buena respuesta ${ }^{45}$.

\section{Sífilis}

Existe una asociación epidemiológica entre sífilis e infección por $\mathrm{VIH}$, las úlceras genitales favorecen la transmisión de Treponema pallidum y éste a su vez, la transmisión del $\mathrm{VIH}^{46}$. Pese a que la incidencia de la sífilis iba en disminución, la llegada del VIH ha vuelto a aumentar las tasas de esta enfermedad ${ }^{32,47,48}$. Son factores de riesgo para adquirir sífilis: ser homosexual, tener historia de una infección de transmisión sexual, tener múltiples parejas sexuales y participar en sexo anal-oral-genital sin protección ${ }^{30}$.

Clínicamente se puede presentar de manera atípica como sífilis primaria con chancro más grave y doloroso, en localizaciones inusuales (Figura 6); como chancros múltiples en $25 \%$ de los pacientes, o incluso llegando a chancros agresivos con perforaciones de labios mayores o prepucio ${ }^{47}$. Algunos autores han reportado una mayor demora en la curación del chancro ${ }^{47,48}$.

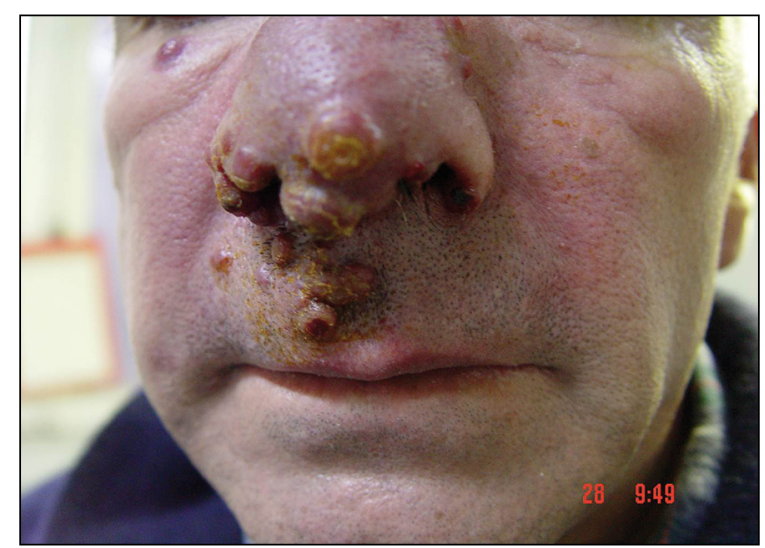

Figura 5. Angiomatosis bacilar. Nódulos y tumores eritematosos múltiples, friables, en la cara. 


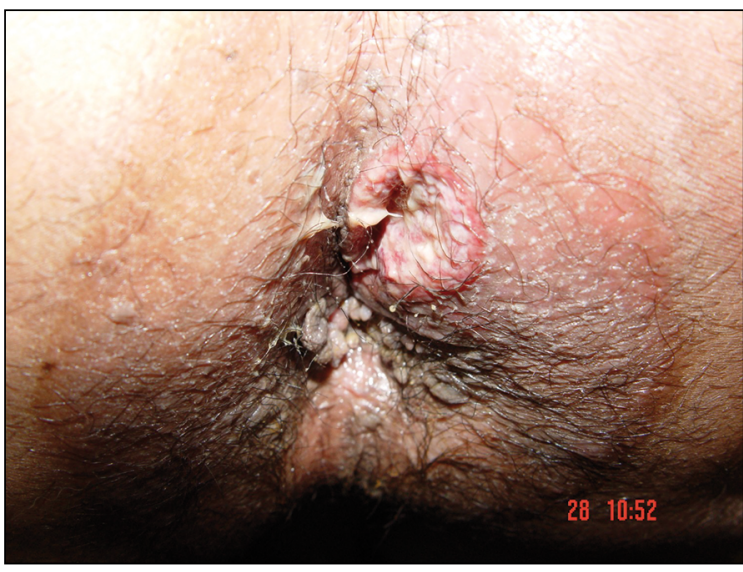

6. Chancro periana Los bordes son indurados.

Figura 7. Sífilis secundaria.

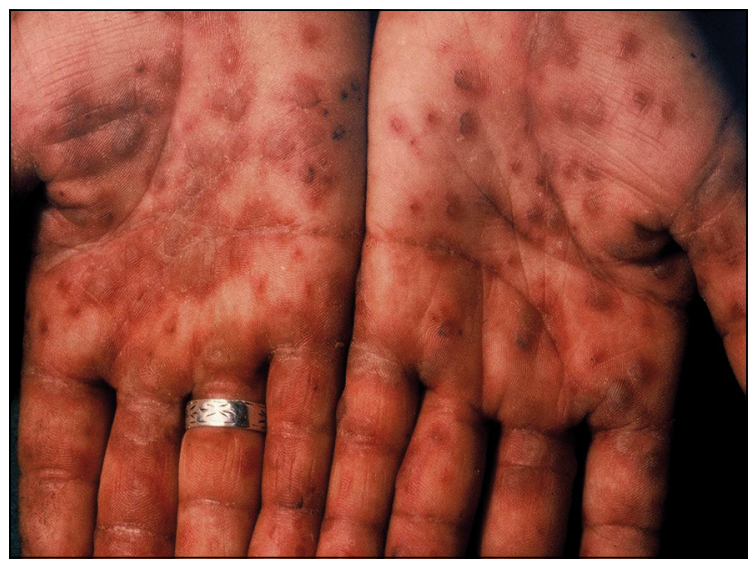

Aproximadamente, $25 \%$ de los pacientes con sífilis primaria, no tratada, progresarán a sífilis secundaria ${ }^{47}$. Esta etapa de la sífilis se manifiesta, en $70 \%$ de las veces, como un rash pápulo-escamoso generalizado con compromiso planto plantar (Figura 7); sin embargo, puede manifestarse como sífilis maligna en $7 \%$ de los pacientes infectados con VIH y sífilis: El cuadro se caracteriza por erupción pápulo-escamosa difusa, con pústulas, nódulos y úlceras con presencia de vasculitis necrosante ${ }^{47,49}$. Los criterios diagnósticos incluyen títulos de tests no treponémicos muy elevados, reacción de Jarisch-Herxheimer y una clara respuesta a tratamiento ${ }^{47}$. En algunos casos, se pueden presentar lesiones de sífilis primaria y secundaria concomitantemente e incluso de sífilis primaria y terciaria en un mismo paciente ${ }^{47,48}$. Otras manifestaciones incluyen la alopecia en 3 a $7 \%$ de los pacientes y las lesiones mucosas, entre muchas otras que escapan a esta revisión ${ }^{47}$.

El diagnóstico se realiza de la misma forma que en pacientes no infectados por VIH pero existen algunos reportes de casos con serologías aberrantes incluyendo la "sífilis seronegativa" (test no-treponémicos y trepo- némicos falsamente negativos). Muchos de estos falsos negativos pueden deberse a fenómenos de "prozona" causado por anticuerpos a títulos muy altos ${ }^{47}$. Del mismo modo, $18 \%$ de los pacientes con sífilis e infección por $\mathrm{VIH}$, no normalizan sus títulos de tests no treponémicos al año de seguimiento pese a haber recibido tratamiento adecuado, generando casos de test no treponémicos falsamente positivos ${ }^{47}$.

La neurosífilis es un tema que escapa a este capítulo; sin embargo, consideramos importante realizar una punción lumbar en pacientes con sífilis que presenten: síntomas y signos neurológicos; evidencia de enfermedad terciara activa; falla a tratamiento sin evidencia clara de reinfección y en pacientes con sífilis y VIH asintomáticos neurológicamente y que tengan VDRL/RPR > 1: 32 ó LTCD4 $<350$ céls $/ \mathrm{mm}^{3}{ }^{48,50,51}$. El riesgo de encontrar un LCR alterado se incrementa aún más si se realiza en pacientes con VDRL/RPR > 1: 32 y LTCD4 < 350 céls/ $\mathrm{mm}^{3}{ }^{51}$.

Bencil-penicilina sigue siendo el antimicrobiano de elección, aun en este grupo de pacientes. Azitromicina, que aparece como alternativa terapéutica en pacientes alérgicos a penicilina, no debe ser utilizada en pacientes con infección por VIH debido a que se han reportado tasas de resistencia bacterianas mayores a $33 \%{ }^{47}$.

La reacción de Jarisch-Herxheimer ocurre con mayor frecuencia en pacientes con sífilis maligna y se discute si su incidencia está elevada per se en todos los pacientes con infección por $\mathrm{VIH}^{47,48}$.

\section{Infecciones virales}

Los virus son los principales patógenos que causan infecciones oportunistas en la enfermedad del VIH, ya sea por activación de la infección subclínica (VPH, Poxvirus) o por reactivación de infecciones latentes (herpes simplex tipo 1 [HSV-1], herpes simplex tipo 2 [VHS-2], virus varicela zoster [VVZ], citomegalovirus [CMV], virus de Epstein-Barr [VEB] y el virus herpes humano tipo 8 [VHH-8]).

En varios estudios, el herpes zoster (HZ) aparece como una de las principales y primeras manifestaciones en los pacientes seropositivos para VIH, llegando hasta $28 \% 0^{7,52}$.

En general, la incidencia de estas infecciones virales se ha reducido notablemente con la TARV, salvo las causadas por el VPH.

\section{Virus herpes simplex (VHS) tipos 1 y 2}

El VHS continúa siendo la causa mundial más frecuente de úlcera genital; en pacientes con infección por VIH puede presentarse de manera atípica o extensa, de forma ulcerativa o hipertrófica-tumoral y de manera crónica (Figura 8$)^{32,53}$. Existe reactivación subclínica de VHS en pacientes con infección por $\mathrm{VIH}$; menos de $10 \%$ de las reactivaciones presentan síntomas. 
Estudios demuestran que la infección aguda y recurrencias por VHS pueden estimular la replicación del VIH y se asocia a un aumento de dos a cuatro veces del riesgo de transmisión del $\mathrm{VIH}^{32}$. Curiosamente, el tratamiento supresor herpético no reduce el riesgo de transmisión del VIH; pero sí reduce la aparición de las úlceras herpéticas causadas por VHS-2, en $73 \%{ }^{54}$.

En los pacientes seropositivos para VIH con recuentos $>100 \mathrm{LTCD} 4 / \mathrm{mm}^{3}$, la infección por VHS 1 y 2 se manifiesta con el cuadro clínico clásico, auto limitado y menos de dos semanas de duración. En la infección por VIH más avanzada, se observa aumento en el número y tamaño de las lesiones, recurrencias más graves y frecuentes, con vesículas y úlceras más dolorosas y profundas, que curan más lentamente e incluso presentan lesiones verrugosas, crónicas, con o sin ulceración. Las infecciones herpéticas crónicas ocurren en $0,2 \%$ de los pacientes con infección por VIH y pese a que se definen como aquellas que duran más de un mes, no es raro que duren meses o incluso años, pasando desapercibidas por largos períodos de tiempo ${ }^{53}$. Puede haber presentaciones atípicas, localizadas en la zona inferior de la espalda, glúteos y regiones perianales, con extensiones hasta de $20 \mathrm{~cm}$ de diámetro.

En pacientes con patologías cutáneas crónicas como dermatitis de contacto, dermatitis atópica o psoriasis, entre otras, puede presentarse una erupción herpética diseminada conocida como "eccema herpético" o "erupción variceliforme de Kaposi”. La mayoría de estos cuadros de herpes diseminado ocurre por el VHS tipo $1^{55}$. No está claro si la infección por VIH produce aumento en la incidencia de esta patología ${ }^{56}$.

\section{Infección por virus varicela zoster (VVZ)}

Los episodios de herpes zoster (HZ) por reactivación del VVZ en pacientes con infección por VIH ocurren con una incidencia 10 veces mayor en comparación a la población general ${ }^{32}$.

Cabe destacar, que el HZ ocurre en etapas precoces de la infección por VIH y que muchas complicaciones como el HZ diseminado y el síndrome de Ramsay-Hunt ocurren incluso con recuentos de LTCD4 elevados. Todo esto sugiere una disfunción de las células T inducida por la infección por VIH que, pese a buen control virológico, jugarían un rol importante en la relación entre $\mathrm{VVZ}_{\text {y VIH}}{ }^{7}$.

Otras manifestaciones de la infección por VVZ en paciente infectados por VIH son la varicela grave que puede ser adquirida de novo o por una reactivación en pacientes con antecedentes de varicela o HZ; en ellos no se presenta con forma dermatomérica y tiene compromiso sistémico frecuente con riesgo vital ${ }^{57}$. Otra forma de presentación es como HZ diseminado (más de 20 lesiones fuera del dermatoma o con compromiso de dermatomas anexos), $\mathrm{HZ}$ necrótico y $\mathrm{HZ}$ recurrente ${ }^{58}$. Existen casos de $\mathrm{HZ}$ crónico (duración de más de un mes) que pueden ser der-

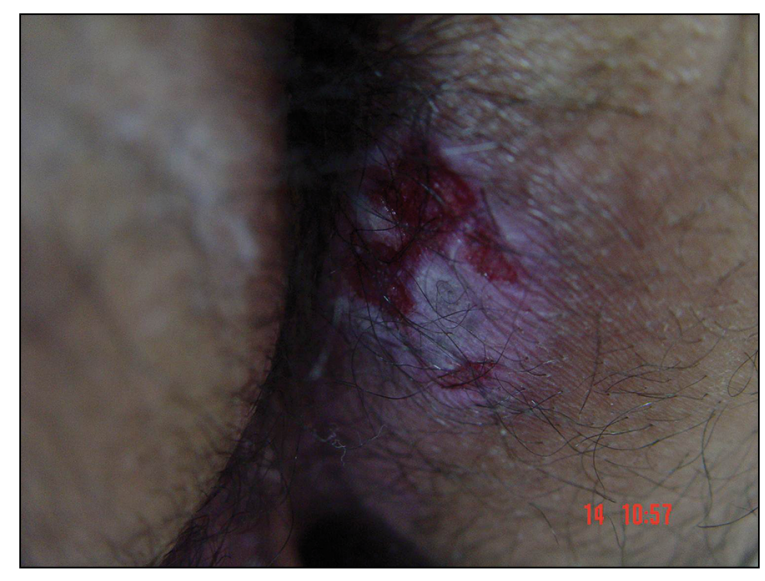

Figura 8. Herpes simplex tipo 2 perianal.

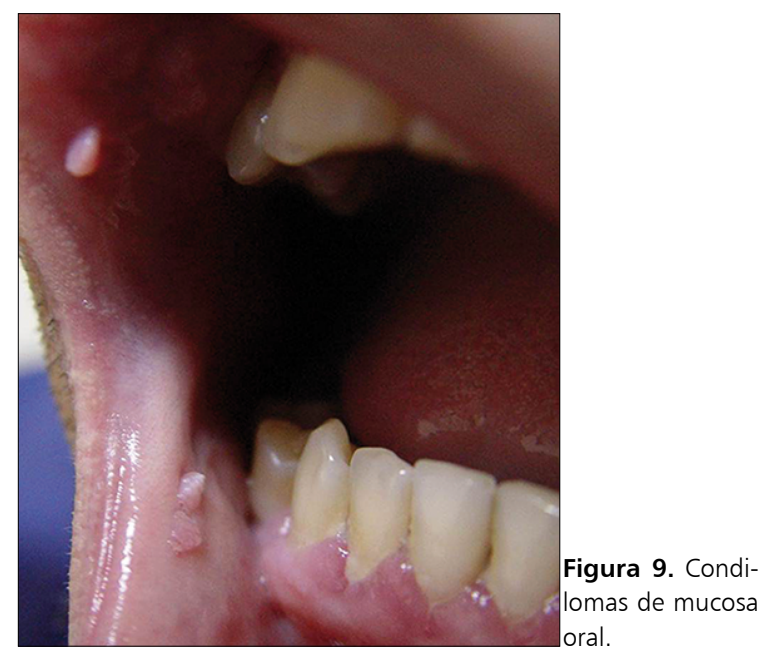

matoméricos o encontrarse sin un patrón de distribución característico, lo que sugiere una forma de diseminación vascular más que neural en estos pacientes ${ }^{53}$.

\section{Virus del papiloma humano (VPH)}

La infección por VPH, manifestada como verrugas y condilomas acuminados (Figura 9), es muy frecuente en los pacientes seropositivos para VIH. Aproximadamente $13 \%$ de los pacientes con infección por VIH presentarán patología ano-rectal; de este grupo $92 \%$ corresponde a condilomas perianales ${ }^{59}$. El tratamiento de los condilomas perianales es muy importante debido al riesgo de desarrollar cáncer anal, como ya fue comentado ${ }^{32}$. Lamentablemente, la incidencia de estas lesiones no tiende a disminuir con la TARV, por lo que deben tratarse activamente. Existen múltiples tratamientos descritos para los condilomas y las verrugas genitales ${ }^{60}$.

En un estudio, el tratamiento con imiquimod al 5\%, tres veces a la semana durante 16 semanas, disminuyó la 
presencia de ADN de VPH de alto riesgo en aproximadamente $50 \%$; sin embargo, el clearence de las lesiones fue sólo de $32 \%{ }^{61}$.

\section{Epidermodisplasia verruciforme adquirida}

La epidermodisplasia verruciforme (EV) es una genodermatosis autosómica dominante rara. Se trata de una inmunosupresión que confiere susceptibilidad a la infección con VPH que no infectan individuos sanos; éstos corresponden al VPH-5 y VPH-8 entre otros ${ }^{62-64}$. La enfermedad se caracteriza por máculas hipopigmentadas (pitiriasis versicolor símiles) en el tronco, extremidades y cara durante la niñez y lesiones parecidas a las verrugas planas en zonas fotoexpuestas. La EV confiere un alto riesgo de desarrollar un carcinoma espinocelular en zonas fotoexpuestas debido a la infección por $\mathrm{VPH}$, lo cual ocurre en 30 a $60 \%$ de los pacientes ${ }^{62}$. Hace algunos años, se describieron pacientes con infección por VIH, sin las alteraciones genéticas clásicas de la EV (mutaciones en los genes EVER 1 y 2), que desarrollaban lesiones similares: esta enfermedad, por tener un patrón común con la EV clásica de déficit en la inmunidad celular, se llamó EV adquirida (EVA) ${ }^{62}$. No hay que confundir los pacientes con EVA con los pacientes con EV clásica que adquieren la infección por VIH de manera tardía en su vida. La EVA también ha sido descrita en otras inmunosupresiones ${ }^{63}$.

Se ha propuesto que esta entidad es más frecuente en pacientes infectados por el VIH de manera vertical o en etapas precoces en su vida, por lo tanto se trataría de pacientes jóvenes. Esto ocurriría debido a que no alcanzarían a generar inmunidad contra este grupo especial de genotipos de VPH; inmunidad que probablemente exista en pacientes adultos que contraen la infección por $\mathrm{VIH}^{62}$.

Figura 10. Múltiples pápulas rosadas-blanquecinas con umbilicación central en la región periocular. La biopsia confirmó el diagnóstico de moluscos contagiosos.
El potencial maligno de la EVA no ha sido demostrado aún, no se sabe si esto se deba a falta de seguimiento (los pacientes con EV clásica desarrollan carcinoma espinocelular en la cuarta década de vida) o es debido a que este riesgo no existe en la EVA.

No disponemos de un tratamiento establecido para la EVA pero se ha intentado retinoides, interferón, imiquimod y terapia fotodinámica, todos con reportes en casos $\operatorname{aislados}^{62}$

\section{Molusco contagioso}

Esta infección viral benigna, autolimitada, se presenta en los niños y adultos jóvenes y es causada por un poxvirus. Ocurre en aproximadamente 10 a $20 \%$ de los pacientes con infección por VIH y es un signo clínico de progresión de la infección por VIH y bajos recuentos de LTCD $4{ }^{65}$. En este grupo de pacientes pueden ser múltiples y extensos, de mayor tamaño, confluentes, desfigurantes (diámetro mayor a $1 \mathrm{~cm}$, verrugosas), de ubicación atípica (cabeza y cuello) y resistentes a los diferentes tratamientos (Figura 10) ${ }^{66}$.

El diagnóstico diferencial de las pápulas umbilicadas incluye clásicamente infecciones por hongos como la criptococosis y la histoplasmosis ${ }^{67}$; sin embargo, este tipo de lesiones se ha asociado también a otras infecciones oportunistas fúngicas y bacterianas como Blastomyces, Coccidiodes, Paracoccidiodes, Sporothrix, micobacterias atípicas, $B$. hensenlae, y patologías neoplásicas como el $\mathrm{SK}^{67}$.

\section{Leucoplasia vellosa oral (LVO)}

Es una lesión de la mucosa oral y de la lengua causada por el virus de Epstein Barr (VEB).

Se caracteriza por la aparición de una o varias placas blanquecinas, no desprendibles, usualmente ubicadas en los bordes laterales de la lengua (Figura 11). Su superficie es usualmente corrugada o puede plegarse formando proyecciones elevadas (vellosas) generalmente bilaterales, pero asimétricas y asintomáticas ${ }^{10}$. Puede simular otras lesiones blanquecinas incluyendo la leucoplasia, liquen plano, carcinoma espinocelular, lengua geográfica y la candidiasis oral, sin compromiso de otras mucosas. Se presenta con frecuencias variables de hasta $25 \%$ en pacientes con infección asintomática por VIH y aumenta su frecuencia al disminuir el recuento de LTCD $4{ }^{10}$.

No es una enfermedad exclusiva de la infección por VIH debido a que se ve también en pacientes receptores de trasplantes. Son factores de riesgo para la LVO ser hombre, recuento de LTCD4 $<200$ céls $/ \mathrm{mm}^{3}$ y alta carga viral.

El diagnóstico se puede realizar con microscopia electrónica e hibridación in situ del ADN del VEB. Generalmente se resuelve con la TARV, lo que la hace un buen indicador de la actividad de la enfermedad y de falla a tratamiento ${ }^{10}$. 
El tratamiento puede realizarse con podofilina. Otros tratamientos que han mostrado respuesta son la cirugía y los antivirales orales e intravenosos ${ }^{68}$.

\section{Infección por citomegalovirus (CMV)}

Las manifestaciones cutáneas aisladas del CMV son poco frecuentes, incluso en pacientes con infección por VIH. Pueden imitar a otras erupciones cutáneas, especialmente las herpéticas. La presentación más común en pacientes seropositivos para VIH son las úlceras extensas en la región perineal con tejido de granulación ${ }^{69}$. La biopsia de piel mostrará infiltración perivascular linfohistiocitaria, con o sin vasculitis; el endotelio de los pequeños vasos dérmicos mostrará células de gran tamaño con inclusiones intranucleares características, con o sin halo.

También se asocia a erupciones máculo-papulares similares a las secundarias a VEB y a rash morbiliforme secundario a la administración de amoxicilina; la infección crónica por $\mathrm{CMV}$ o VEB podría explicar el aumento de las RAM en pacientes con $\mathrm{VIH}^{69}$.

\section{Infecciones fúngicas}

La infección por VIH produce una disregulación inmunológica con un predominio de citoquinas $\mathrm{Th} 2$, disminuyendo la capacidad de los macrófagos para eliminar microorganismos intracelulares; esto lleva a una mayor incidencia de infecciones por hongos ${ }^{70}$.

\section{Candidiasis}

Desde el comienzo de la epidemia del SIDA se determinó la infección por Candida spp como un marcador de falla inmunológica (Figura 12). Además, es la infección oportunista más frecuente en muchas series, llegando a $90 \%$ de prevalencia ${ }^{7,8,10,70}$. Es causada principalmente por Candida albicans pero también por C. glabrata, C. tropicalis, C. krusei y C. parapsilosis. Esto cobra importancia debido a que $C$. glabrata y $C$. krusei son resistentes a fluconazol ${ }^{70}$. Puede ocurrir en cualquier momento de la enfermedad pero la inmunodeficiencia y disminución en los recuentos de LTCD4 aumentan su incidencia ${ }^{10,70}$. El uso de TARV disminuye la prevalencia de candidiasis orofaríngea.

La candidiasis esofágica se describe como una complicación de la candidiasis oral; en pocas ocasiones puede llevar a hemorragia digestiva alta con perforación de la pared gástrica o intestinal ${ }^{70}$.

La candidiasis diseminada es muy infrecuente y se presenta en usuarios de drogas intravenosas, como una foliculitis $^{71,72}$.

Otras manifestaciones incluyen onicomicosis con paroniquia, onicodistrofia, intértrigo y candidiasis vaginal recurrente crónica; es inusual el compromiso sistémico y la fungemia ${ }^{70}$.

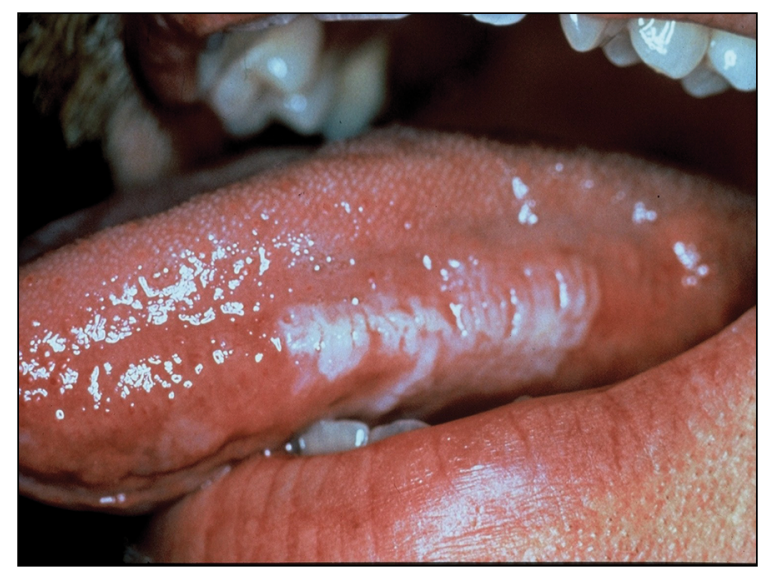

Figura 11. Leucoplasia vellosa oral.

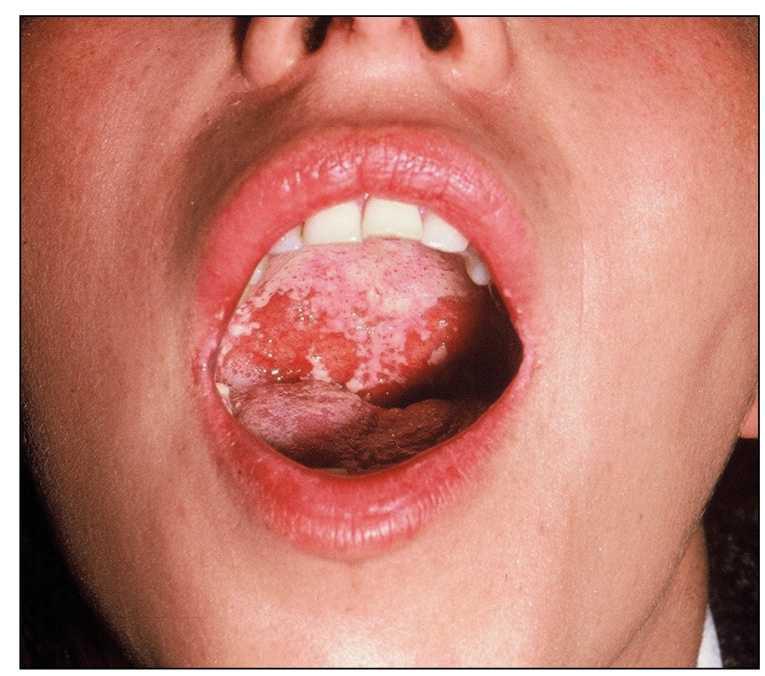

Figura 12. Candidiasis oral.

\section{Dermatofitosis}

Causadas por Tricophyton, Microsporum y Epidermophyton. De éstos, el hongo más frecuente, al igual que en inmunocompetentes, es T. rubrum. En los pacientes con infección por VIH, las infecciones por dermatofitos pueden ser asintomáticas extensas (Figura 13), diseminadas con compromiso de las cuatro extremidades, de múltiples uñas (Figura 14), de presentación atípica y con mala respuesta a tratamiento.

El compromiso dérmico profundo por dermatofitos es poco frecuente y es un marcador de inmunosupresión. Estas lesiones aparecen en áreas con micosis superficiales crónicas y se presentan como ulceraciones múltiples y nódulos fluctuantes. El granuloma de Majocchi (perifoliculitis granulomatosa nodular) es un ejemplo de compromiso dérmico por dermatofitos. Se caracteriza por la presencia de nódulos eritemato-violáceos firmes asociado a onicomicosis, tinea corporis o tinea pedis ${ }^{70}$.

Por otro lado, este grupo de pacientes puede tener 
Figura 13. Tiña facial extensa.

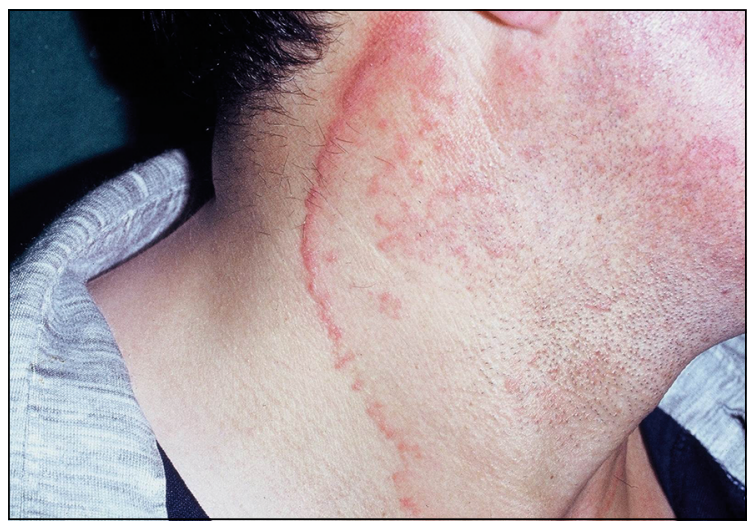

Figura 14. Onicomicosis pedis. Múltiples uñas con infección micótica por dermatofitos.

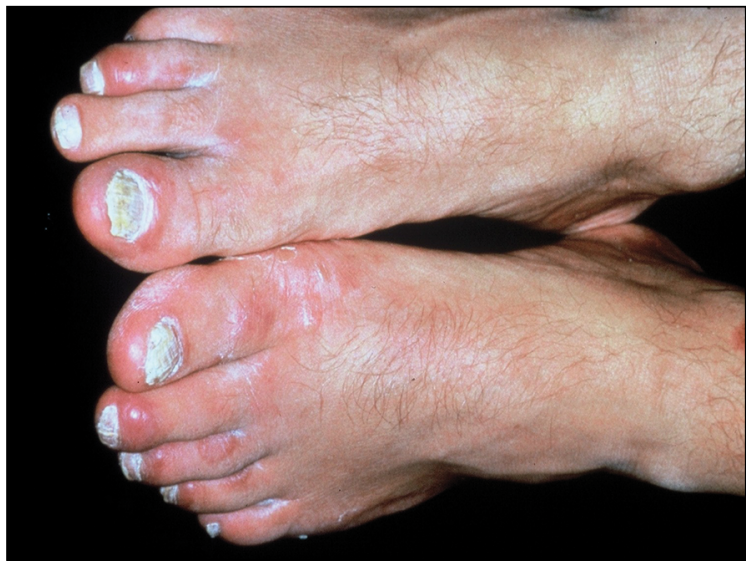

infecciones por hongos no dermatofitos como Fusarium spp, Acremonium spp, Aspergillus spp, Scopulariopsis spp, Onychocola spp, entre otros. Este grupo de hongos puede diseminarse y causar micosis invasoras sistémicas (pulmonares, endoftalmitis, etc.) y fungemia, por lo cual deben ser tratadas ${ }^{73}$.

\section{Infecciones fúngicas invasoras}

Pueden surgir por invasión local de piel o mucosa o por activación de un foco de infección pulmonar latente de criptococosis, histoplasmosis, coccidiomicosis, esporotricosis o penicilliosis y difundir a distintos órganos (pulmones y meninges clásicamente) y piel, en 5 a $15 \%$ en personas con enfermedad avanzada por VIH (recuentos de LTCD4 $<50$ céls $/ \mathrm{mm}^{3}$ ). Las manifestaciones cutáneas más frecuentes son semejantes al molusco contagioso ${ }^{67,74}$.

\section{Criptococosis}

Enfermedad causada por la levadura Cryptococcus neoformans. Su forma diseminada es una de las micosis subcutáneas fatales más comunes en pacientes con infec- ción por VIH/SIDA; se consideran pacientes en riesgo aquellos con LTCD $4<100$ céls $/ \mathrm{mm}^{3}{ }^{74}$. Se contagia generalmente por inhalación de las levaduras desde las palomas u otras aves y genera focos pulmonares.

Las lesiones cutáneas se presentan en $10 \%$ de los pacientes con compromiso sistémico (secundario a siembra hematógena desde focos pulmonares) y se localizan con mayor frecuencia en la cabeza y el cuello, pudiendo ser generalizadas ${ }^{67}$. La morfología cutánea más frecuente es tipo molusco contagioso (pápulas o nódulos color piel-rosados, umbilicados), pudiendo tener necrosis o ulceración central ${ }^{67}$; otras lesiones cutáneas en la criptococosis son las pústulas, celulitis, ulceración, paniculitis, púrpura palpable, abscesos subcutáneos, placas vegetantes y lesiones similares a pioderma gangrenoso ${ }^{67,75}$. La infección cutánea primaria es excepcional y es usualmente secundaria a trauma local en ambientes donde el hongo es prevalente; produce un patrón linfangítico de distribución esporotricoide $^{76}$.

El tratamiento de elección es anfotericina B intravenosa asociado a flucitosina oral seguido de fluconazol oral, pese al cual se describe alta letalidad por la infección ${ }^{67}$.

\section{Histoplasmosis}

Enfermedad causada por el hongo dimórfico geográfico Histoplasma capsulatum. Se contagia por las deposiciones de los murciélagos, clásicamente en cuevas ${ }^{74}$. En nuestro país no existe el microorganismo pero es endémico en las zonas de los trópicos ${ }^{77}$. Ocurre en $5 \%$ de los pacientes con infección por VIH que viven en áreas no endémicas y en $27 \%$ de los que viven en áreas endémicas ${ }^{74}$.

El compromiso cutáneo ocurre en $11 \%$ de los pacientes por siembra hematógena, generalmente de un foco pulmonar, en los casos de histoplasmosis diseminadas ${ }^{74}$. Este compromiso pareciera ser mayor en pacientes latinoamericanos pudiendo llegar hasta $85 \%$ de los $\operatorname{casos}^{78}$.

Clínicamente se presenta como máculas eritematosas, pápulas y nódulos tipo molusco contagioso ${ }^{67}$, pústulas, lesiones acneiformes, úlceras o placas vegetantes. Puede comprometer la mucosa oral en 25 a $45 \%$ de los casos ${ }^{79}$.

Anfotericina B sigue siendo el fármaco de elección en los casos de histoplasmosis diseminada.

\section{Peniciliosis}

Enfermedad causada por el hongo dimórfico Penicillium marneffei. Es frecuente en pacientes con infección por VIH del sudeste asiático y sur de China ${ }^{74}$. La exposición laboral al suelo en la estación lluviosa de las zonas asiáticas es considerada un factor de riesgo. Puede ocurrir en forma localizada en pacientes inmunocompetentes pero en pacientes inmunosuprimidos se presenta en forma diseminada, principalmente en pacientes con recuentos de LTCD4 < 100/ $/ \mathrm{mm}^{3}{ }^{80}$. Las lesiones cutáneas ocurren en 70 a $85 \%$ de los pacientes con compromiso sistémi- 
$\mathrm{co}^{74,80,81}$. Clínicamente se observan pápulas umbilicadas tipo molusco contagioso; abscesos y nódulos subcutáneos, ubicados principalmente en la cara y el cuello ${ }^{81}$. Además pueden presentarse úlceras y pápulas con exudado amarillento, en la mucosa oral ${ }^{74}$.

\section{Coccidiomicosis, esporotricosis y aspergilosis}

En general las infecciones por Coccidioides immitis, Sporothrix schenkii, Aspergillus fumigatus y Aspergillus flavus se presentan como lesiones cutáneas diseminadas asintomáticas; muchas de ellas, con apariencia moluscosímil, secundarias a siembra cutánea desde un foco sistémico. Sin embargo, algunas pueden manifestarse como infecciones cutáneas diseminadas en ausencia de compromiso sistémico objetivable ${ }^{74,82}$. Aspergillus spp pueden causar enfermedad cutánea primaria por inoculación directa (bajo cinta adhesiva de catéteres venosos centrales $)^{74}$.

\section{Infecciones parasitarias}

Las infecciones causadas por parásitos se encuentran frecuentemente en pacientes con infección por VIH. Debido a su estado inmunitario, se encuentran en mayor riesgo de contraer infecciones por Leishmania, escabiosis y existen algunos reportes de aumento del riesgo de Toxoplasma $\mathrm{spp}^{83}$.

\section{Escabiosis}

La infestación causada por Sarcoptes scabiei var hominis se presenta de manera atípica en este grupo de pacientes, en forma papular/nodular diseminada y en su forma hiperqueratósica ("sarna noruega"). Esta forma puede ser letal debido a sepsis de foco cutáneo por sobreinfección bacteriana. La forma noruega ocurre con mayor frecuencia cuando el recuento de LTCD4 es $<200$ céls $/ \mathrm{mm}^{3}{ }^{83}$. Del mismo modo, puede presentarse como parte del $\mathrm{SRI}^{84}$ o simulando otras dermatosis como dermatitis de contacto generalizada, psoriasis o enfermedad de Darier ${ }^{83}$. Por esta razón, debe considerarse el diagnóstico diferencial de escabiosis en cualquier paciente seropositivo para VIH que se presente con prurito como motivo de consulta.

Pese a que la escabiosis en pacientes inmunocompetentes no compromete el cuero cabelludo, los pacientes con infección por VIH/SIDA pueden tener compromiso de ese sitio anatómico ${ }^{83,84}$. En este grupo de pacientes, sobre todo los que se presentan con sarna noruega, el tratamiento con ivermectina y permetrina asociado a algún queratolítico como vaselina azufrada ha tenido buenos resultados ${ }^{85}$.

\section{Leishmaniasis}

Enfermedad causada por protozoos del género Leishmania. Tiene tres formas de presentación: cutánea (LC), muco-cutánea (LMC) y visceral (LV o kala-azar, del hindi "fiebre negra"). Aproximadamente dos tercios de los casos son LC o LMC y sólo un tercio corresponde a $\mathrm{LV}^{86}$. Por lo tanto, la mayoría de las infecciones por Leishmania spp. permanecen localizadas en la piel y los ganglios linfáticos loco-regionales.

En general, los pacientes con infección por VIH pueden presentar formas de LC diseminadas ( $>10$ lesiones pleomórficas en más de dos sitios corporales no contiguos) y formas difusas (primarias cutáneas o por diseminación en forma hematógena $)^{87}$. Además, tienen mayor riesgo de desarrollar compromiso de mucosas, el cual no debe ser categorizado como una LMC debido a que no tiene el período de latencia clásico ${ }^{88}$.

Sin embargo, más que las formas cutáneas de leishmaniasis, la infección por VIH confiere un riesgo aumentado de 100 a 1.000 veces de presentar formas de LV, lo que ha llevado a autores a proponer la inclusión de la LV como una patología definitoria de SIDA $^{89-91}$.

\section{Conclusiones}

Los pacientes con infección por VIH pueden presentar una serie de manifestaciones dermatológicas con variadas etiologías. Muchas de éstas son inespecíficas y requerirán un detallado algoritmo diagnóstico.

Debido al aumento en el número de pacientes que padecen esta infección crónica, es muy probable que nos veamos enfrentados a alguna de estas manifestaciones durante nuestra práctica diaria, por lo que debemos conocerlas a cabalidad para poder brindar ayuda a este grupo importante de pacientes.

\section{Resumen}

La epidemia del virus de la inmunodeficiencia humana (VIH) sumado al mayor acceso a terapias anti-retrovirales (TARV) han llevado a un aumento del número y la sobrevida de pacientes que viven con esta infección crónica. Se estima que hasta $95 \%$ de los pacientes con infección por VIH/SIDA presentarán alguna manifestación cutánea, por lo cual, debemos conocerlas. En la presente revisión se estudiarán las manifestaciones cutáneas de la infección por el VIH/SIDA clasificadas como: manifestaciones inflamatorias, manifestaciones asociadas a la TARV, manifestaciones neoplásicas y manifestaciones infecciosas asociadas a infección por VIH/SIDA (bacterianas, virales, fúngicas y parasitarias). Estas manifestaciones deben ser reconocidas por los médicos y el personal de salud a cargo del tratamiento y control de los pacientes con esta patología crónica. 


\section{Referencias bibliográficas}

1.- Piot P, Quinn T C. Response to the AIDS pandemic-a global health model. N Engl J Med 2013; 368: 2210-8.

2.- Brandt A M. How AIDS invented global health. N Engl J Med 2013; 368: 2149-52.

3.- Cohen M S, Shaw G M, McMichael A J, Haynes B F. Acute HIV-1 Infection. N Engl J Med 2011; 364: 1943-54.

4.- Introcaso C E, Hines J M, Kovarik C L. Cutaneous toxicities of antiretroviral therapy for HIV: part I. Lipodystrophy syndrome, nucleoside reverse transcriptase inhibitors, and protease inhibitors. J Am Acad Dermatol 2010; 63: 549-61.

5.- Global AIDS response progress reporting 2012. Geneva: Joint United Nations Programme on HIV/AIDS (UNAIDS), 2011

6.- Cáceres K, Álvarez P, Ortíz E, en representación del Departamento de Epidemiología. Ministerio de Salud. Informe Nacional. Evolución de la infección por VIH/SIDA. Chile 1984-2012. Rev Chilena Infectol 2014; 31 (Supl 1): 7-33.

7.- Josephine M, Issac E, George A, Ngole M, Albert S E. Patterns of skin manifestations and their relationships with CD4 counts among HIV/ AIDS patients in Cameroon. Int J Dermatol 2006; 45: 280-4.

8.- Jing W, Ismail R. Mucocutaneous manifestations of HIV infection: a retrospective analysis of 145 cases in a Chinese population in Malaysia. Int J Dermatol 1999; 38: 457-63.

9.- Cedeno-Laurent F, Gómez-Flores M, Méndez N, Ancer-Rodríguez J, Bryant J L, Gaspari A A, et al. New insights into HIV-1primary skin disorders. J Int AIDS Soc 2011; 14: 5 .

10.- Rigopoulos D, Paparizos V, Katsambas A. Cutaneous markers of HIV infection. Clin Dermatol 2004; 22: 487-98.

11.- Khambaty M M, Hsu S S. Dermatology of the patient with HIV. Emerg Med Clin North Am 2010; 28: 355-68

12.- Hurt C, Tammaro D. Diagnostic evaluation of mononucleosis-like illnesses. Am J Med 2007; 120: 911.e1-8.

13.- Tindall B, Barker S, Donovan B, Barnes T, Roberts J, Kronenberg C, et al. Characterization of the acute clinical illness associated with human immunodeficiency virus infection. Arch Intern Med 1988; 148: 945-9.

14.- Rodwell G E, Berger T G. Pruritus and cutaneous inflammatory conditions in HIV disease. Clin Dermatol 2000; 18: 479-84.

15.- Alessi E, Cusini M, Zerboni R. Mucocutaneous manifestations in patients infected with human immunodeficiency virus. J Am Acad Dermatol 1988; 19: 290-7.

16.- Serling S L, Leslie K, Maurer T. Approach to pruritus in the adult HIV-positive patient. Semin Cutan Med Surg 2011; 30: 101-6.
17.- Leal L, Ribera M, Daudén E. Psoriasis and HIV infection. Actas Dermosifiliogr 2008; 99: 753 63.

18.- Coldiron B M, Bergstresser P R. Prevalence and clinical spectrum of skin disease in patients infected with human immunodeficiency virus. Arch Dermatol 1989; 125: 357-61.

19.- García Río I, Díaz-Ramón J L, González-Pérez R, Arregui Murua M A, Trébol Urra I, Tamayo V C, et al. Ofuji's disease: description of a case. Actas Dermosifiliogr 2006; 97: 391-4.

20.- Annam V, Yelikar B R, Inamadar A C, Palit A, Arathi P. Clinicopathological study of itchy folliculitis in HIV-infected patients. Indian J Dermatol Venereol Leprol 2010; 76: 259-62.

21.- Afonso J P, Tomimori J, Michalany N S, Nonogaki S, Porro A M. Pruritic papular eruption and eosinophilic folliculitis associated with human immunodeficiency virus (HIV) infection: a histopathological and immunohistochemical comparative study. J Am Acad Dermatol 2012; 67: 269-75.

22.- Navarini A A, Stoeckle M, Navarini S, Mossdorf E, Jullu B S, Mchomvu R, et al. Antihistamines are superior to topical steroids in managing human immunodeficiency virus (HIV)-associated papular pruritic eruption. Int J Dermatol 2010; 49: 83-6.

23.- Blanes M, Belinchón I, Portilla J. Cutaneous drug reactions in HIV-infected patients in the HAART era. Actas Dermosifiliogr 2009; 100: 253-65.

24.- Kong H H, Myers S A. Cutaneous effects of highly active antiretroviral therapy in HIVinfected patients. Dermatol Ther 2005; 18: 58-66.

25.- Reust C E. Common adverse effects of antiretroviral therapy for HIV disease. Am Fam Physician 2011; 83: 1443-51.

26.- Introcaso C E, Hines J M, Kovarik C L. Cutaneous toxicities of antiretroviral therapy for HIV: part II. Nonnucleoside reverse transcriptase inhibitors, entry and fusion inhibitors, integrase inhibitors, and immune reconstitution syndrome. J Am Acad Dermatol 2010; 63: 563-9.

27.- Vogt T, Brockmeyer N, Kutzner H, Schöfer H. Brief 1 D. Guidelines-Cutaneous angiosarcoma and Kaposi sarcoma. J Dtsch Dermatol Ges 2013; 11: 2-9, 2-10.

28.- Casper C, Krantz E M, Corey L, Kuntz S R, Wang J, Selke S, et al. Valganciclovir for suppression of human herpesvirus- 8 replication: a randomized, double-blind, placebo-controlled, crossover trial. J Infect Dis 2008; 198: 23-30.

29.- Honda K S. HIV and skin cancer. Dermatol Clin 2006; 24: 521-30.

30.- Silverberg M J, Leyden W, Warton E M, Quesenberry C P Jr, Engels EA, Asgari M M. HIV infection status, immunodeficiency, and the incidence of non-melanoma skin cancer. J Natl Cancer Inst 2013; 105: 350-60.
31.- Olsen C M, Knight L L, Green A C. Risk of melanoma in people with HIV/AIDS in the pre- and post-HAART eras: a systematic review and meta-analysis of cohort studies. PLoS One 2014; 9: e95096.

32.- Rodgers S, Leslie K S. Skin infections in HIVinfected individuals in the era of HAART. Curr Opin Infect Dis 2011; 24: 124-9.

33.- Hidalgo-Tenorio C, Rivero-Rodríguez M, Gil-Anguita C, López De Hierro M, Palma P, Ramírez-Taboada J, et al. Antiretroviral therapy as a factor protective against anal dysplasia in HIV-infected males who have sex with males. PLoS One 2014; 9: e92376.

34.- Kreuter A, Wieland U. Human papilloma virusassociated diseases in HIV-infected men who have sex with men. Curr Opin Infect Dis 2009; 22: 109-14.

35.- Grulich A E, van Leeuwen M T, Falster M O, Vajdic C M. Incidence of cancers in people with HIV/AIDS compared with immunosuppressed transplant recipients: a meta-analysis. Lancet 2007; 370: 59-67.

36.- Kreuter A, Brockmeyer N H, Weissenborn S J, Gambichler T, Stücker M, Altmeyer P, et al. Penile intraepithelial neoplasia is frequent in HIV-positive men with anal dysplasia. J Invest Dermatol 2008; 128: 2316-24.

37.- Hansra N K, Shinkai K. Cutaneous communityacquired and hospital-acquired methicillinresistant Staphylococcus aureus. Dermatol Ther 2011; 24: 263-72.

38.- Balcells M M E. Tuberculosis in HIV positive individuals. Rev Chilena Infectol 2009; 26: 126-34.

39.- Lasso B M. Diagnosis and treatment of opportunistic infections in HIV/AIDS adult patients. Rev Chilena Infectol 2011; 28: 440-60.

40.- Concha R M, Fich S F, Rabagliati B R, Pinto S C, Rubio L R, Navea D O, et al. Cutaneous tuberculosis: two case reports and review. Rev Chilena Infectol 2011; 28: 262-8.

41.- High W A, Evans C C, Hoang M P. Cutaneous miliary tuberculosis in two patients with HIV infection. J Am Acad Dermatol 2004; 50: S110-3.

42.- Dodiuk-Gad R, Dyachenko P, Ziv M, Shani-Adir A, Oren Y, Mendelovici S, et al. Nontuberculous mycobacterial infections of the skin: A retrospective study of 25 cases. J Am Acad Dermatol 2007; 57: 413-20.

43.- Elston D. Nontuberculous mycobacterial skin infections: recognition and management. Am J Clin Dermatol 2009; 10: 281-5

44.- Mendiratta V, Mittal S, Jain A, Chander R. Mucocutaneous manifestations in children with human immunodeficiency virus infection. Indian J Dermatol Venereol Leprol 2010; 76 : 458-66.

45.- Uribe P, Balcells M E, Giesen L, Cárdenas C, García P, González S. Bacillary angiomatosis. Rev Med Chile 2012; 140: 910-4. 
46.- Lynn W A, Lightman S. Syphilis and HIV: a dangerous combination. Lancet Infect Dis 2004; 4: 456-66.

47.- Stevenson J, Heath M. Syphilis and HIV infection: an update. Dermatol Clin 2006; 24: 497-507.

48.- Karp G, Schlaeffer F, Jotkowitz A, Riesenberg K. Syphilis and HIV co-infection. Eur J Intern Med 2009; 20: 9-13.

49.- Corti M, Solari R, De Carolis L, Figueiras O, Vittar N, Maronna E. Malignant syphilis in a patient infected by human immunodeficiency virus. Case report and literature review. Rev Chilena Infectol 2012; 29: 678-81.

50.- Ghanem K G, Moore R D, Rompalo A M, Erbelding E J, Zenilman J M, Gebo K A. Lumbar puncture in HIV-infected patients with syphilis and no neurologic symptoms. Clin Infect Dis 2009; 48: 816-21.

51.- Dumaresq J, Langevin S, Gagnon S, Serhir B, Deligne B, Tremblay C, et al. Clinical prediction and diagnosis of neurosyphilis in HIV-infected patients with early syphilis. J Clin Microbiol 2013; 51: 4060-6.

52.- Shobhana A, Guha S K, Neogi D K. Mucocutaneous manifestations of HIV infection. Indian J Dermatol Venereol Leprol 2004; 70: 82-6.

53.- Wauters O, Lebas E, Nikkels A F. Chronic mucocutaneous herpes simplex virus and varicella zoster virus infections. J Am Acad Dermatol 2012; 66: e217-27.

54.- Celum C, Wald A, Lingappa J R, Magaret A S, Wang R S, Mugo N, et al. Acyclovir and transmission of HIV-1 from persons infected with HIV-1 and HSV-2. N Engl J Med 2010; 362: 427-39.

55.- Schroeder H F, Elgueta N A, Martínez G M J. Eczema herpeticum caused by herpes simplex virus type 2. Review of the literature about one case. Rev Chilena Infectol 2009; 26: 356-9.

56.- Rodríguez-Serna M, Mercader P, Pardo J, Fortea-Baixauli J M, Aliaga A. Kaposi's varicelliform eruption in an HIV-positive patient after laser resurfacing. J Eur Acad Dermatol Venereol 2004; 18: 711-2.

57.- Ong C W, Ang B S, Lee C C. Severe varicella infection occurring after herpes zoster reactivation in a patient with AIDS. Br Med J Case Rep 2009; 2009.

58.- Shin B S, Na C H, Song I G, Choi K C. A case of human immunodeficiency virus infection initially presented with disseminated herpes zoster. Ann Dermatol 2010; 22: 199-202.

59.- Muñoz C C, Mansilla E J A, Heider C C, Leal W M J, Chain A C. Prevalence of anorectal pathology in HIV/AIDS patients. Rev Chilena Infectol 2012; 29: 95-8.

60.- Concha R M. Diagnosis and treatment of human papilloma virus. Rev Chilena Infectol 2007; 24:
209-14.

61.- Saiag P, Bauhofer A, Bouscarat F, Aquilina C, Ortonne J P, Dupin N, et al. Imiquimod 5\% cream for external genital or perianal warts in human immunodeficiency virus-positive patients treated with highly active antiretroviral therapy: an open-label, noncomparative study. Br J Dermatol 2009; 161: 904-9.

62.- Castro-Pérez G A, Sorin I, Bravo A I, Mazzuoccolo L D. Acquired epidermodysplasia verruciformis in a patient with congenital HIV infection. Actas Dermosifiliogr 2013; 104: 731-3.

63.- Zampetti A, Giurdanella F, Manco S, Linder D, Gnarra M, Guerriero G, et al. Acquired epidermodysplasia verruciformis: a comprehensive review and a proposal for treatment. Dermatol Surg 2013; 39: 974-80.

64.- Rogers H D, Macgregor J L, Nord K M, Tyring S, Rady P, Engler D E, et al. Acquired epidermodysplasia verruciformis. J Am Acad Dermatol 2009; 60: 315-20.

65.- Massa A F, Borges-Costa J, Soares-Almeida L, Sacramento-Marques M. Molluscum contagiosum eyelid lesions in an HIV-patient. Dermatol Online J 2013; 19: 10.

66.- Theiler M, Kempf W, Kerl K, French L E, Hofbauer G F. Disseminated molluscum contagiosum in a HIV-positive child. Improvement after therapy with 5\% imiquimod. J Dermatol Case Rep 2011; 5: 19-23.

67.- de Souza J A. Molluscum or a mimic? Am J Med 2006; 119: 927-9.

68.- Baccaglini L, Atkinson J C, Patton L L, Glick M, Ficarra G, Peterson D E. Management of oral lesions in HIV-positive patients. Oral Surg Oral Med Oral Pathol Oral Radiol Endod 2007; 103: S50.e1-23.

69.- Badr Abdull Gaffar, Raman L G, Al Muala A. Cutaneous cytomegalovirus infection in a patient with acquired immunodeficiency syndrome. Int J Dermatol 2008; 47: 944-6.

70.- Ramos-E-Silva M, Lima C M, Schechtman R C, Trope B M, Carneiro S. Superficial mycoses in immunodepressed patients (AIDS). Clin Dermatol 2010; 28: 217-25.

71.- Recio C, Piqué E, Lluch J, Vidal J M. Candida folliculitis in intravenous drug users. Enferm Infecc Microbiol Clin 2003; 21: 386-7.

72.- Buño-Ramilo B, Fernández-Fernández F J, Álvarez-Díaz H, Mariño A. Candida folliculitis in intravenous drug user. Med Clin (Barc) 2009; 132: 568

73.- Hwang S M, Suh M K, Ha G Y. Onychomycosis due to nondermatophytic molds. Ann Dermatol 2012; 24: 175-80.

74.- Ramos-e-Silva M, Lima C M, Schechtman R C, Trope B M, Carneiro S. Systemic mycoses in immunodepressed patients (AIDS). Clin Dermatol 2012; 30: 616-27.
75.- Ni W, Huang Q, Cui J. Disseminated cryptococcosis initially presenting as cellulitis in a patient suffering from nephrotic syndrome. BMC Nephrol 2013; 14: 20.

76.- Negroni R. Cryptococcosis. Clin Dermatol 2012; 30: 599-609.

77.- Wolff M. Outbreak of acute histoplasmosis in Chilean travelers to the ecuadorian jungle: an example of geographic medicine. Rev Med Chile 1999; 127: 1359-64.

78.- Marques S A, Silvares M R, de Camargo R M, Marques M E. Cutaneous histoplasmosis disclosing an HIV-infection. An Bras Dermatol 2013; 88: 420-3.

79.- Vidyanath S, Shameena P, Sudha S, Nair R G. Disseminated histoplasmosis with oral and cutaneous manifestations. J Oral Maxillofac Pathol 2013; 17: 139-42.

80.- Larsson M, Nguyen L H, Wertheim H F, Dao T T, Taylor W, Horby P, et al. Clinical characteristics and outcome of Penicillium marneffei infection among HIV-infected patients in northern Vietnam. AIDS Res Ther 2012; 9: 24

81.- Yap F B, Thevarajah S, Asmah J. Penicillium marneffei infection in an African man. Dermatol Online J 2010; 16: 2.

82.- Vásquez-del-Mercado E, Arenas R, PadillaDesgarenes C. Sporotrichosis. Clin Dermatol 2012; 30: 437-43.

83.- Giamarellou H. AIDS and the skin: parasitic diseases. Clin Dermatol 2000; 18: 433-9.

84.- Fernández-Sánchez M, Saeb-Lima M, Alvarado-de la Barrera C, Reyes-Terán G Crusted scabies-associated immune reconstitution inflammatory syndrome. BMC Infect Dis 2012; 12: 323.

85.- Karthikeyan K. Crusted scabies. Indian J Dermatol Venereol Leprol 2009; 75: 340-7.

86.- Murray H W, Berman J D, Davies C R, Saravia N G. Advances in leishmaniasis. Lancet 2005; 366: 1561-77.

87.- Bailey M S, Lockwood D N. Cutaneous leishmaniasis. Clin Dermatol 2007; 25: 203-11.

88.- David C V, Craft N. Cutaneous and mucocutaneous leishmaniasis. Dermatol Ther 2009; 22: 491-502.

89.- Olea P. Visceral leishmaniasis in patient with HIV infection. Rev Chilena Infectol 2013; 30: 216-20.

90.- Chaudhary R G, Bilimoria F E, Katare S K. Diffuse cutaneous leishmaniasis: co-infection with human immunodeficiency virus (HIV). Indian J Dermatol Venereol Leprol 2008; 74 : 641-3.

91.- Ezra N, Ochoa M T, Craft N. Human immunodeficiency virus and leishmaniasis. J Glob Infect Dis 2010; 2: 248-57. 